WellBeing International

WBI Studies Repository

6-1995

\title{
Mirror Use by African Grey Parrots (Psittacus erithacus)
}

Irene M. Pepperberg

University of Arizona

Sean E. Garcia

University of Arizona

Eric C. Jackson

University of Arizona

Sharon Marconi

University of Arizona

Follow this and additional works at: https://www.wellbeingintlstudiesrepository.org/acwp_asie

Part of the Animal Studies Commons, Comparative Psychology Commons, and the Other Animal Sciences Commons

\section{Recommended Citation}

Pepperberg, I. M., Garcia, S. E., Jackson, E. C., \& Marconi, S. (1995). Mirror use by African Grey parrots (Psittacus erithacus). Journal of Comparative Psychology, 109(2), 182.

This material is brought to you for free and open access by WellBeing International. It has been accepted for inclusion by an authorized administrator of the WBI Studies Repository. For more information, please contact wbisr-info@wellbeingintl.org.

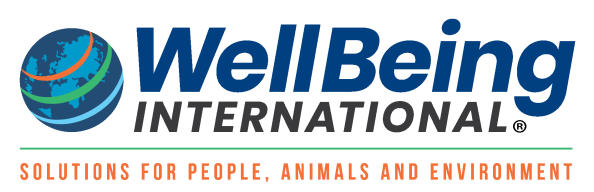




\section{Mirror Use by African Grey Parrots (Psittacus erithacus)}

Irene M. Pepperberg, Sean E. Garcia, Eric C. Jackson, and Sharon Marconi

University of Arizona

\section{$\underline{\text { ABSTRACT }}$}

Two Grey parrots (Psittacus erithacus) were tested on various types of mirror use: mirror image stimulation, mirror-mediated object discrimination, and a simple form of mirror-mediated spatial locating. During exposure to a mirror, neither bird clearly demonstrated self-exploratory behavior but responded instead in ways similar to those of marmosets, monkeys, dolphins, extremely young children $(<18$ months), and to the initial responses of orangutans and young chimpanzees. The parrots' behavior was not a consequence of an inability to process mirrored information, because in subsequent tasks they used mirrors to discriminate among exemplars and to locate hidden objects; these birds are the first nonmammalian subjects to exhibit all these behavior patterns. Their behavior on all the tasks can be compared to that of humans, great apes, dolphins, monkeys, and Asian elephants.

Mirror studies generally have two goals. One goal is to determine whether subjects demonstrate selfrecognition (e.g. Anderson. 1984; Gallup. 1970; Povinelli. Rulf, Landau, \& Bierschwale, 1993; Swartz \& Evans, 1991) and, by extension, self-awareness and advanced social cognition (e.g., Gallup. 1991; Mitchell, 1993). A second goal is to learn whether subjects that fail standard tests of self-recognition do so because they lack capacities for processing mirror information (e.g. Menzel, Savage-Rumbaugh, \& Lawson, 1985; Povinelli, 1989). Studies usually include mirror-image stimulation, mirror-triggered search, mirror-mediated object discrimination, mirror-mediated spatial locating, and mirror-guided reaching. After describing what each of these tasks requires of a subject, we suggest a third goal for mirror studies: to provide data for cross-species comparisons of cognitive and perceptual abilities.

During mirror-image stimulation, subjects generally view a reflection of their entire body (Amsterdam, 1972; Gallup. 1970). The length and number of mirror exposures varies among studies; data consist of the type, number, and sometimes length of the observed mirror interactions. Mirror-image stimulation is most often used to test self-recognition, but it also provides data on the developmental stage of children (Amsterdam, 1972) ${ }^{1}$ and. for animals, on how extensively visual (rather than acoustic or olfactory) cues mediate interactions in a given species (Anderson, 1984).

Mirror-triggered search is the most basic task in which mirrors are used to find hidden objects (Povinelli. 1989). Subjects learn that desirable items are likely found in a few fixed locations in the presence of a mirror. The subject need not correlate the object's location and information in the mirror; a mirror is merely a cue to begin a search (see Anderson. 1986; Menzel et al., 1985). Subjects who engage in mirror- 
triggered searches are not necessarily able to use mirrors to locate, without trial and error, rewards that are hidden in novel sites.

In mirror-mediated object discrimination, unlike mirror-triggered search, a subject uses a mirror to choose between objects (e.g., hidden rewards and aversive stimuli). A subject must recognize some correlation between an object and its reflection (Menzel et al.. 1985), but the subject need not understand that the image is a representation of the actual object nor use the mirror to monitor its actions. Subsequent appropriate responses to novel positive and negative objects in familiar locations rule out the possibility of mirror-triggered search.

Mirror-mediated spatial locating and mirror-guided reaching require more advanced capacities. In the former task, subjects use mirrors to locate, without trial and error, items hidden in novel locations. Here a subject shows that it understands the correspondence between the location of the object in real space and reflected information (Povinelli, 1989). Only in the latter task, however, must a subject also relate its own movements to those depicted in the mirror (e.g., a sequence of fine hand movements; Itakura, 1987; Menzel et al., 1985; Povinelli, 1989).

Mirror use thus examines not only self-recognition but also how animals respond to reflections and process information about spatially displaced objects and actions. Specifically, because various mirror tasks require different levels of information processing, we suggest that mirror studies can provide a hierarchical scale for assessing and comparing perceptual and cognitive abilities of diverse species. Animals that, for example, succeed on mirror-mediated discriminations but fail tests of mirror-mediated locating demonstrate specific cognitive deficits compared with those that pass both tests. Of particular interest are comparisons between mammals and nonmammals because of their neurological and anatomical differences.

Several researchers have examined mirror use in nonhuman mammals. Mirror-image stimulation has been studied in pygmy marmosets (Cebuella pygma; Eglash \& Snowdon, 1983); elephants (Elep/ws maximus; Povinelli, 1989); dolphins (Tursiops truncatus; Marino, Reiss, \& Gallup, 1994); chimpanzees (Pan troglodytes; Gallup, 1970); orangutans (Pongo pygmaeus; Robert, 1986; Suarez \& Gallup, 1981); and various monkey species (see reviews in Anderson, 1984, and Gallup, 1991). Although only some of the great apes unequivocally demonstrate self-recognition (see review in Anderson, 1993), other mammals can use mirrored information in various ways. Elephants (Povinelli, 1989) and monkeys (e.g., Cebus capucinus, Marchal \& Anderson, 1993; Macaca mulatta, Anderson) 1986; Menzel et al., 1985; Macaca fuscata fuscata, Itakura, 1987) were tested on mirror-triggered search and spatial locating, and monkeys can perform mirror-mediated object discriminations. Monkeys (Itakura, 1987; Menzel et al., 1985) and chimpanzees (Menzel et al., 1985) have been tested on mirror-guided reaching. The question now is whether such capacities are limited to mammals.

With the exception of mirror-image stimulation studies that failed to show self-recognition (budgerigars [Melopsittacus undulatus] and house sparrows [Passer domesticus domesticus], Gallup \& Capper, 1970; a kea [Nestor notabilis], Diamond \& Bond, 1989; chickadees [Parus atricapillus], Censky \& Ficken, 1982; zebra finches [Poephila guttata], Ryan, 1978; glaucous-winged gulls [Larus glaucescens], Stout, Wilcox, \& Creitz, 1969; blue grouse [Dendragapus obscurus], Stirling, 1968; cedar waxwings [Bombycilla cedrorum] and juncos [junco hyemalis], Andrews, 1966; and lovebirds [Agapornis roseicollis], Delsaut \& Roy, 1980), ${ }^{2}$ no comparable work has been performed on birds. Specifically, can subjects whose brains are organized so differently from those of mammals (Striedter, 1994) and who lack hands and comparable feet (and thus certain fine motor skills) use mirrored information in a manner similar to that of mammals? Given that a Grey parrot (Psittacus erithacus) has demonstrated cognitive capacities similar to those of nonhuman primates and marine mammals (e.g., comprehension of concepts of category, 
number, same-different, absence of information, relative size; Pepperberg, 1990a, 1990c, 1992, 1994a; Pepperberg \& Brezinsky, 1991), this species would be a good subject for studies of avian mirror use. We therefore tested two Grey parrots on mirror-image stimulation, mirror-mediated object discrimination, and mirror-mediated spatial locating. Each study was designed both to test for capacities comparable to those of mammals and to accommodate avian anatomy. Experiments on mirror-guided reaching form the basis of a separate study (see General Discussion).

\section{Experiment 1. Mirror-Image Stimulation}

Our first goal was to examine our subjects' reactions to their mirror images. Even if they failed to exhibit those self-exploratory reactions that provide the rationale for conducting a test for self-recognition (Gallup \& Povinelli, 1993), we could compare our birds to mammals with respect to social, aggressive, and search behavior. Too, because mirror use may develop with experience (Amsterdam, 1972; Anderson, 1984; Field \& Hogg, 1992; Gallup, 1987), our subjects required exposure to mirrors before we tested skills involving discrimination and locating.

\section{Method}

\section{Subjects and Housing}

Subjects were hand-raised juvenile Grey parrots: Alo (female, 11 mos) and Kyaaro (male, 7.5 mos). They lived in separate rooms but had had social interaction with other Grey parrots at their breeding facility and with each other for their first month in the laboratory. They were part of an ongoing experiment on vocal learning and cognition (Pepperbcrg, 1990a, 1993). When experiments were not in progress, birds could be atop their cages, on "gyms" (branches nailed together) or parrot stands. Birds were confined to Hoei cages $(38 \times 71 \times 56 \mathrm{~cm})$ when humans were absent and for sleeping. Water, Harrison's Bird Diet, vegetables, fruit, dried pastas, and cereals were provided when neither testing nor training were in progress. Before our study, their only exposures to reflections were occasional views of themselves in water at the bottom of a sink when caretakers washed dishes.

\section{Apparatus and Procedure}

We used a glass mirror, $45 \times 29.5 \mathrm{~cm}$, with a brown, $2.5 \mathrm{~cm}$ plastic frame. On all but six trials, the mirror leaned against a wall, with the $45 \mathrm{~cm}$ edge resting on a laboratory bench countertop. The mirror was angled to provide ample space for a "behind-the-mirror" search. A parrot could view its entire body and range over the entire counter $(205 \times 68 \mathrm{~cm})$. To eliminate possible distractions, we removed all other objects from the counter. For two trials for each bird, we placed the mirror so birds could walk on it. Birds also received four trials each with the mirror placed in an open drawer under the counter so they could look down to view their reflections.

As a control, two additional trials were administered with a nonreflective surface: We angled the mirror as just described but covered its surface with cardboard. We could thereby determine whether the reflective surface or merely the presence of the apparatus elicited the parrots' responses.

Exposure to the mirror, uncovered and covered, was limited to specific trials. Trials occurred at different times on different weekdays so that the mirror was not associated with any other activity. Ala's first eight mirror trials were $1 \mathrm{hr}$, but subsequent trials were $30 \mathrm{~min}$ because of her limited attention span. Kyaaro's trials were only $15 \mathrm{~min}$ for two reasons: First, we wished to see if overall length of exposure affected behavior; second, his attention span for any task was shorter than Ala's. Ala's 21 trials took place from July to October 1991; Kyaaro's 23 trials spanned the period from August 1991 to May 1992. ${ }^{3}$ 
We collected data in real-time and also videotaped several complete and partial trials. An observer (Eric C. Jackson or Sharon Marconi) sat across the room from the birds. Before data collection began, birds were habituated, in the absence of the mirror, to the observer and video system. The observer operated the camera to ensure that the birds were always in view. The parrots' frequent movements precluded use of a stationary system in the absence of humans.

We confirmed coding of behavioral data through interobserver reliability scores. For the categories described later, we compared codings of three live sessions (by Eric C. Jackson or Sharon Marconi) with those of the corresponding videos (by Irene M. Pepperberg) for each bird. We computed Pearson correlation coefficients for coded behaviors for which there were at least three instances on the data sheets for one tape or session.

\section{Results}

Neither bird attended to the covered mirror. When placed in front of it, they walked away. The results differ from those obtained by Anderson and Bayart (1985), whose monkeys showed immediate significant interest in a nonreflective surface after ceasing to respond to the mirror. Thus any attention our birds showed to the mirror was a consequence of its reflective surface.

In the presence of the mirrored surface, both birds engaged in some categories of behavior described for children (Amsterdam, 1972), chimpanzees (Lin, Bard, \& Anderson, 1992), marmosets (Eglash \& Snowdon, 1983), and dolphins (Marino et al., 1994): (a) little or no interest, (b) social behavior toward the mirror or image (including aggressive acts), (c) searching behind the mirror, and (d) avoidance (Table 1). We also observed behavior unique to birds: preening and ruffling feathers. For both birds, the mean number of times they produced a behavior was often less than the standard deviation across trials (Table 1). For Alo and Kyaaro, the mean number of overall reactions were, respectively, $10.87(S D=9.56)$ and $33.76(S D=9.18)$

Neither bird habituated to the vertical mirror. For Alo, no significant correlation existed between date of session and lack of interest, $R^{2}=.073, F(13,15)=1.03, p=.329$; social acts, $R^{2}=.07, F(13,15)=0.98$, $p=.340$; aggressive acts, $R^{2}=.099, F(13,15)=1.44, p=.252$; or searching (one instance only). For Kyaaro, no significant correlation existed between date of session and lack of interest, $R^{2}=.060, F(15$, $17)=.954, p=.344$; social acts, $R^{2}=.069, F(13,17)=1.14, p=.302$; or searching, $R^{2}=.008, F(15,17)$ $=.12, p=n s$; but his aggressive acts significantly decreased over time: Session date and number of acts were negatively correlated (-.58), and a linear regression demonstrated a small significant interaction, $R^{2}$ $=.335, F(15,17)=7.56, p=.015$.

Some behavior patterns were unique to each bird. During three sessions with a vertical mirror, Alo put a foot against the mirror and placed her head so as to provide a simultaneous view of her foot and its mirror image. This behavior was often correlated with scratching her foot against the mirrored surface. In two sessions, Kyaaro engaged in what is called "peekaboo" in children: He stared at the mirror image, moved sideways until his head was just out of range of the mirror, then quickly moved back into view. In other sessions he said "you come," "you climb," or "tickle" to the mirror.

Interobserver reliability figures that could be calculated were as follows: for Alo, beak touch to mirror, .95; to/fro movement with respect to mirror, .87; peck frame, .95; preen, .98; head down to mirror, 1.0; for Kyaaro, tap mirror, .87; preen, .95; grab edge of frame, .87; fluff/ruffle, 1.0; walk away, .5; head down, .5; vocalize, .98; scratch, .95. For Kyaaro, only one disagreement existed in the "walk away" category, but the small number of samples (2-3 codings per session) caused the effect of the disagreement to be large. 
In the "head down" category, only two codings differed; in both cases, an additional entry was made from videotape. "Head down" behavior is extremely brief and could easily have been missed in real time.

\section{Discussion}

Kyaaro was more consistent than Ala, but the mean number of times either bird produced a given behavior was often less than the standard deviation across trials. Differences across trials, however, seemed more indicative of a parrot's general activity level on a given day than its interest in the mirror. Thus, despite variations in numbers of reactions per trial, we believe that the birds' behavior patterns were salient.

The data suggest that both birds viewed the mirror image as a conspecific. Only Ala's repeated unique act of scratching while viewing her foot and its image simultaneously suggests a search for a correspondence between her actions and those in the mirror. Other actions-beak tapping, preening, and vocalizing-cannot be interpreted unequivocally but are similar to ones that occur when two birds are together.

Both parrots often tapped the mirror with opened beaks. Such behavior resembles "beak wrestling" responses to a conspecific, during which birds approach one another with open beaks, then intertwine beaks and engage in pushing, pulling, and sideways maneuvers. Opened-beak tapping might, however, be interpreted as a self-guided action: Open-mouth postures of dolphins in front of a mirror are seen either as exploratory or threat behavior (Marino et al., 1994), as are the actions of monkeys who both touch and threaten their mirror images (Anderson, 1984).

Preening and head-scratching may be self-directed, but parrors often engage in such behavior when alone or with conspecifics (Wolter, 1987). Grooming body parts that are observable only with mirrors suggests self-recognition (Gallup, 1987), but parrots, unlike primates, see all body areas except parts of their heads. Their behavior may thus be like that of some monkeys who increase self-scratching in the presence of conspecifics and mirror images (e.g., Hall, 1962). Moreover, the action of bending their heads toward the mirror was likely related to preening: Both birds (and a third parrot, Alex) thereby attempt to elicit preening from trainers and each other (note Wolter, 1987). Thus, our subjects' preening and head-scratching behavior in front of the mirror are likely social responses to perceived conspecifics.

Because these parrots are part of a study on learned vocal communication (Pepperberg, 1994b), we noted their vocal behavior in the presence of a mirror. Kyaaro vocalized (e.g., "you come," "tickle") while attending to his reflection but may have directed his utterances to the trainer rather than his image (i.e., not to "another" parrot). Such utterances are also common in solitary sound play (see Pepperberg, Brese, \& Harris, 1991). Alo, in contrast, vocalized only once to the mirror in the absence of other vocal stimuli (e.g., voices outside her room). Absence of auditory feedback, like the absence of olfactory cues for dogs (Gallup, 1987), may have affected her behavior. Lovebirds, for example, prefer perches that provide mirrors and auditory input to perches that provide only mirrors (Delsaut \& Roy, 1980). Parrots use vocal cues in social interactions (Gnam, 1988; Mebes, 1978); without such cues, vocal responses may have become irrelevant. 
Table 1. Reactions to Mirror Image Stimulation

\begin{tabular}{|c|c|c|c|c|c|c|c|c|c|}
\hline \multirow[b]{3}{*}{ Behavior } & \multicolumn{9}{|c|}{ Total number of times behavior observed } \\
\hline & \multicolumn{3}{|c|}{$\begin{array}{c}\text { Mirror vertical } \\
\text { (15 trials) }\end{array}$} & \multicolumn{3}{|c|}{$\begin{array}{l}\text { Mirror under counter } \\
\text { ( } 4 \text { trials) }\end{array}$} & \multicolumn{3}{|c|}{$\begin{array}{c}\text { Mirror horizontal } \\
\text { (2 trials) }\end{array}$} \\
\hline & No. & $M$ & $S D$ & No. & $M$ & $S D$ & No. & $M$ & $S D$ \\
\hline \multicolumn{10}{|c|}{ A: Alo } \\
\hline \multicolumn{10}{|l|}{ Little or no interest } \\
\hline Reach toward observer & 20 & 1.34 & 1.63 & 0 & & & 0 & & \\
\hline Peck at herself & 0 & & & 2 & .50 & .71 & 1 & .50 & .71 \\
\hline Reach toward cage/floor & 1 & .06 & .26 & 0 & & & 0 & & \\
\hline Peck at frame & 23 & 1.53 & 2.13 & 1 & .25 & .50 & 1 & .50 & .71 \\
\hline Receive tickles & 6 & .40 & .63 & 0 & & & 0 & & \\
\hline \multicolumn{10}{|l|}{ Social behavior } \\
\hline Put head between her legs & 8 & .53 & 1.13 & 0 & & & 0 & & \\
\hline Lift foot toward mirror & 12 & .80 & 2.04 & 0 & & & 0 & & \\
\hline Stretch neck & 8 & .53 & 1.13 & 0 & & & 0 & & \\
\hline Walk in circles on mirror & NA & & & 2 & .50 & 1.0 & 3 & 1.50 & .71 \\
\hline Bob head & 1 & .06 & .26 & 0 & & & 0 & & \\
\hline Move to/fro in relation to mirror & 8 & .53 & .92 & 1 & .25 & .50 & 0 & & \\
\hline Aggression (full feather display) & 10 & .66 & 1.11 & 2 & .50 & 1.0 & 0 & & \\
\hline Touch beak to mirror & 30 & 2.00 & 2.10 & 0 & & & 0 & & \\
\hline Tap beak at mirror & 0 & & & 4 & 1.00 & .82 & 5 & 2.50 & 3.54 \\
\hline Open beak at mirror & 0 & & & 4 & 1.00 & 1.16 & 0 & & \\
\hline Put head down toward mirror & 12 & .80 & 1.01 & 3 & .75 & .96 & 0 & & \\
\hline Rub body against mirror & 5 & .34 & .90 & 0 & & & 0 & & \\
\hline Preen $^{a}$ & 16 & 1.07 & 1.39 & 2 & .50 & .58 & 3 & 1.50 & 2.12 \\
\hline Vocalize $^{a}$ & 0 & & & 1 & .25 & .50 & 0 & & \\
\hline \multicolumn{10}{|l|}{ Searching behavior } \\
\hline Look behind mirror & 1 & .06 & .26 & 0 & & & 0 & & \\
\hline \multicolumn{10}{|l|}{ Avoidance behavior } \\
\hline Fear & 0 & & & 2 & .50 & .58 & 0 & & \\
\hline \multicolumn{10}{|l|}{ Other } \\
\hline Look under counter & NA & & & 6 & 1.50 & 1.30 & NA & & \\
\hline Reach for object on mirror & NA & & & 4 & 1.00 & .82 & NA & & \\
\hline Pacing & 0 & & & 2 & .50 & .58 & 0 & & \\
\hline "Curious" looks at mirror" & 0 & & & 11 & 2.75 & 3.10 & 5 & 2.50 & 3.54 \\
\hline & & B: & aaro & & & & & & \\
\hline \multicolumn{10}{|l|}{ Little or no interest } \\
\hline Walk away & 41 & 2.41 & 2.00 & 8 & 2.00 & 1.83 & 3 & 1.50 & .71 \\
\hline Walk toward observer & 5 & .29 & .47 & 0 & & & 0 & & \\
\hline Watch observer & 9 & .53 & .80 & 0 & & & 2 & 1.00 & 1.41 \\
\hline Chew toes & 1 & .06 & .24 & 0 & & & 0 & & \\
\hline Grab frame & 97 & 5.71 & 2.89 & 18 & 4.50 & 3.11 & 4 & 2.00 & 2.82 \\
\hline \multicolumn{10}{|l|}{ Social behavior } \\
\hline Move toward mirror & 3 & .18 & .39 & 0 & & & 0 & & \\
\hline Put head down toward mirror & 49 & 2.88 & 2.06 & 9 & 2.25 & 1.50 & 9 & 4.50 & 2.12 \\
\hline Tap beak at mirror & 104 & 6.12 & 2.89 & 18 & 4.50 & 2.08 & 13 & 6.50 & 2.12 \\
\hline Fluffs/ruffles ${ }^{c}$ & 41 & 2.18 & 2.01 & 3 & .75 & .96 & 1 & .50 & .71 \\
\hline Stare at herself & 28 & 1.65 & 1.62 & 5 & 1.25 & 2.50 & 3 & 1.50 & 2.12 \\
\hline Preen/Scratch ${ }^{a}$ & 77 & 3.88 & 1.99 & 15 & 3.75 & 3.30 & 10 & 5.00 & 1.41 \\
\hline Vocalize $^{\mathrm{a}}$ & 116 & 7.00 & 4.12 & 63 & 15.75 & 11.27 & 13 & 6.50 & 9.19 \\
\hline "Peekaboo"d & 3 & .18 & .53 & 1 & .25 & .50 & 0 & & \\
\hline \multicolumn{10}{|l|}{ Searching behavior } \\
\hline Look behind/over edge of mirror & 19 & 1.12 & 1.54 & 0 & & & 5 & 2.50 & 2.12 \\
\hline \multicolumn{10}{|l|}{ Other } \\
\hline Appear to watch observer in mirror & 3 & .18 & .53 & 0 & & & 0 & & \\
\hline Look under counter & NA & & & 11 & 2.75 & 3.20 & NA & & \\
\hline
\end{tabular}

${ }^{a}$ This behavior could be self- or other-directed (see text). ${ }^{b}$ "Curious" describes a look in which the pupils flash (change in size) while the bird has its head close to the mirror. ${ }^{c}$ This behavior is generally considered aggressive. ${ }^{d}$ "Peekaboo" labels a behavior that would be so described in children. 
Data on exposure to the horizontal mirror demonstrate the need for future research. ${ }^{4}$ Both birds reacted somewhat more aggressively (e.g., AJo with rapid approaches and withdrawals, with erect feathers and open beak; Kyaaro with ruffles and fluffs) to the upright than to the horizontal mirror (Table 1). Alo responded aggressively to the vertical mirror 10 times $(M=.067, S D=1.113)$; Kyaaro, 41 times $(M=$ $2.18, S D=2.01)$. On all types of horizontal trials, Alo reacted aggressively only twice $(M=.34, S D=$ $0.516)$; Kyaaro reacted aggressively four times $(M=.67, S D=0.817)$. Although the difference in number of aggressive acts for Kyaaro was significant $(t=2.42, p<.05)$, this result may be confounded because Kyaaro's aggression to the upright mirror declined over time and horizontal trials were interspersed among vertical ones. Nevertheless, differences in aggressive reactions may be real: An upright mirror presents an image like a conspecific; the image in a flat mirror is one birds might see in a reflective surface in the wild (e.g., a pool of water). Possibly, exposure to horizontal rather than vertical mirrors might facilitate self-recognition. We are examining further the differences between horizontal and vertical presentations.

Kyaaro and Alo also exhibited search behavior. Kyaaro, the younger bird, persisted in searching, but no significant correlation existed between this behavior and exposure time. Alo searched only in her first session. Such behavior is common in subjects who do not demonstrate mirror self-recognition: children 7 to 14 months old (Amsterdam, 1972; cf. Dixon, 1957), elephants (Povinelli, 1989), and several monkey species (Anderson, 1984). Such behavior suggests that the reflected image is regarded as another individual (Gallup, 1968).

Both birds, but particularly the elder, Alo, did not simply ignore the mirror in several sessions but actively walked away from it and toward the observer. In children, such behavior emerges in their second year, before self-recognition but after the age at which they search for their image. Amsterdam (1972) suggests that such behavior is a precursor to self-recognition (e.g., the image is no longer viewed as a "playmate"), but for animals this reaction is interpreted as avoidance of an apparent abnormally behaving conspecific (Anderson \& Bayart, 1985; Zazzo, 1979).

For some mammals, youth and sometimes exposure can affect mirror responses; conceivably, our birds reacted similarly. Children must he around 2 years old, chimpanzees even older, and both may need adequate mirror exposure (Brooks-Gunn \& Lewis, 1984; cf. Povinelli et al., 1993) before demonstrating self-exploratory patterns (e.g., novel mouth movements they follow in a mirror, using a mirror to guide their hands to scratch their faces; Lin et al., 1992) that indicate that a mark test for self-recognition (Gallup, 1970) might be successful. Parrot lifespans are comparable to those of chimpanzees and humans, and at least one species (kea) has a similarly extended juvenile learning stage (Diamond \& Bond, 1991). Our birds were under 2 years old and had limited mirror exposure (14.5 hr for Alo, $5.75 \mathrm{hr}$ for Kyaaro) compared with that for dolphins (33 hr, Marino et al., 1994) or some chimpanzees (80 hr, Gallup, 1970; but see Povinelli et al., 1993). Alo, the elder, who had more mirror exposure, responded more similarly to older children. Moreover, Alo, in a separate study, demonstrated some interest in markings (red, yellow, blue Sharpie) placed on her feet while she was anesthetized for a nonsurgical procedure. Marking was done late one evening; the next morning, when fully recovered from the anesthesia, she noticed the marks as she walked toward her breakfast and spent 1 min alternating between walking and intently staring and chewing at her feet. Such intense staring was never observed during baseline trials, although chewing was common. For these reasons, studies of mirror-image stimulation are continuing and tests for self-recognition are planned.

However, because our birds did not clearly exhibit self-exploratory behavior patterns, we proceeded at this time to test them instead on other forms of mirror use that would compare their cognitive capacities to those of mammals. Such a goal was reasonable because our data suggested they might engage in mirror-mediated object discrimination and spatial locating: They both looked under and explored the 
hidden edge of a mirror placed under a counter (Table 1). We thus decided to proceed with these two tasks, testing the one that required less advanced cognitive skills first.

\section{Experiment 2. Mirror-Mediated Object Discrimination}

Several species of monkey (Brown, McDowell, \& Robinson, 1965; Itakura, 1987; Menzel et al., 1985; Tinklepaugh, 1928) and at least one fish (Barbus; Moody, 1975) learn to use mirror images to discriminate among objects. Discriminatory capacity per se is not important, because mirror-mediated discriminations should be no more difficult than those involving real objects (Menzel et al., 1985; but see Lohmann, Delius, Hollard, \& Friesel, 1988). The mirror-mediated task is, however, a control for mirrortriggered search: A subject that performs mirror-mediated object discrimination is not using a mirror simply as a cue to begin automatic searching in a familiar location. We therefore tested whether our birds would use information from a mirror to retrieve positive items hidden in a box and leave the test area when hidden stimuli were aversive.

Figure 1. Apparatus for mirror-mediated object discrimination: Box used to hide the designated object is at an angle to the mirror.

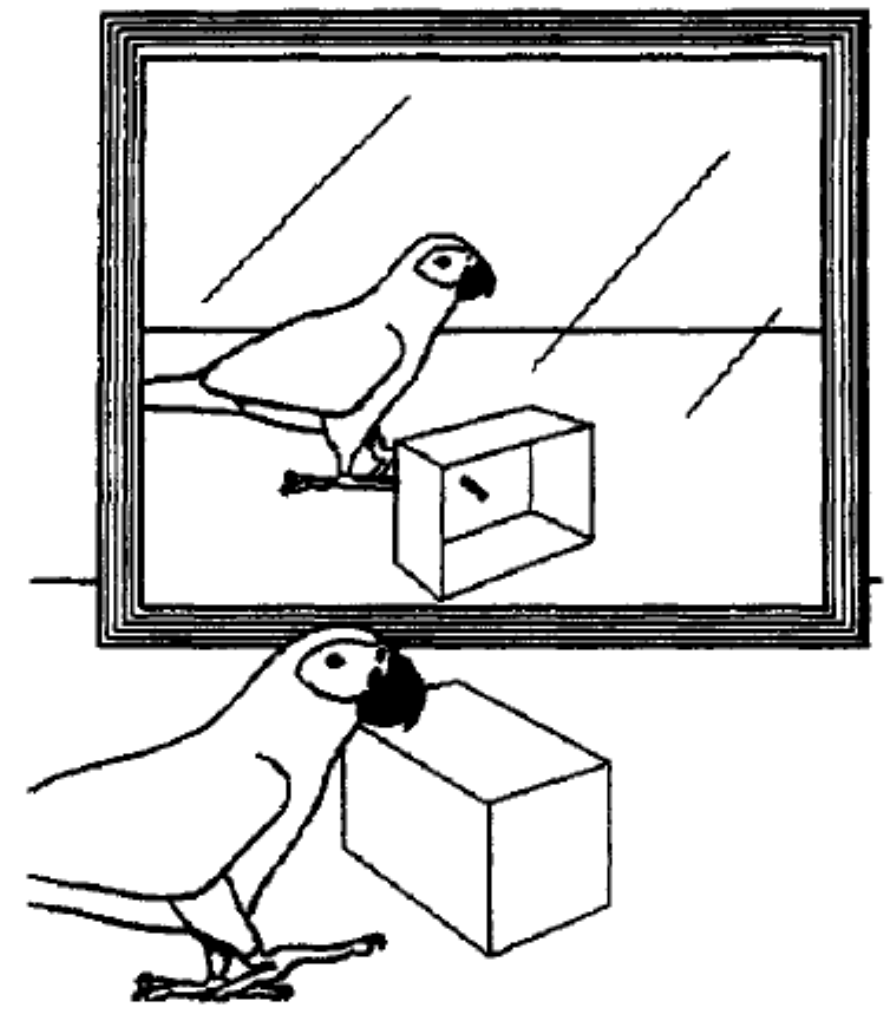

\section{Method}

\section{Subjects and Housing}

The subjects and their housing were identical to those in Experiment 1.

\section{Apparatus and Procedure}

We used the mirror and countertop from Experiment 1 . We placed a cardboard box $(16 \times 11 \times 7.5 \mathrm{~cm})$ so its side was $6 \mathrm{~cm}$ from that of the mirror; the open end was either parallel to and $25 \mathrm{~cm}$ from the front of 
the mirror or rotated by $45^{\circ}$ (Figure 1). Subjects could see inside only by using the mirror. We used rewards (piece of dry pasta) versus no reward as a go/no-go task on habituation trials. ${ }^{5}$ Test trials used positive rewards (for Alo, pasta; for Kyaaro, a wooden spool or a plastic cup) versus negative stimuli (for Alo, some plastic toy animals; for Kyaaro, pipe cleaners and rubber or plastic toys in the first round of testing and in the second, a small version of the towel that had been used to restrain him for medical treatments). We categorized stimuli as positive or negative on the basis of a bird's initial reaction when the items were introduced into its play area. We ran additional trials with novel items. For Alo, positive novel items were a large ball bearing, plastic balls, toy trucks, wooden pencils, a clicking metal toy frog; negative objects were new plastic toy animals. For Kyaaro, novel positive items were pasta, pens, a role of tape, and leather strips; we retained the towel as the negative item.

Although we usually avoid food rewards (Pepperberg, 1990b), pasta was a particularly potent reward for Alo. To ensure that she located pasta by sight and not odor, we ran control tests before and after the experiment. A student held Alo so that she could not see around the student's body; another student placed pasta in easily accessible locations that were or were not directly visible. Alo located the pasta in 10 of 10 visually accessible trials and did not search in 10 of 10 hidden trials, $x^{2}(1, N=20)=20.00, p<$ .0001. Pasta thus did not emit olfactory cues sufficient to elicit search behavior.

Habituation trials. A trial began when one of us placed a bird on a perch out of sight of the box. This person next performed either a real or sham baiting of the box. Presence or absence of pasta was determined by a coin flip. Being careful to avoid looking at the mirror or bird, this person put the bird on the counter in a predetermined position, situated him- or herself out of direct sight of the box, then recorded the subject's behavior. Trials lasted until the bird reacted to the mirror or $15 \mathrm{~min}$ had elapsed. As in Experiment 1, we conducted trials at different times on different days of the week. Alo had $22 \mathrm{go} / \mathrm{no}-\mathrm{go}$ habituation trials; Kyaaro had 20.

Test trials. Test trials differed from habituation trials in three ways. First, we used negative stimuli in place of an empty box and varied the positive rewards. Second, the box's position varied in one third of the trials (Figure 1), so a bird not only had to walk around the edge of the box but also away from the mirror to obtain the hidden object. Third, two thirds of Alo's and half of Kyaaro's test trials used additional controls against experimenter cuing: On these trials, a student who did not know what was positive and negative for a given bird baited the box, positioned the parrot appropriately, and then left the room. The observer, who could not observe this process and could not see into the box, then collected data.

The number of trials differed for each parrot. Alo received 120 trials, evenly divided between positive and negative stimuli, between June 1992 and April 1993, with breaks for surgery. Kyaaro received 143 positive and 105 negative trials between October 1992 and June 1993, with breaks for surgery. Kyaaro had more trials for four reasons: First, he had received less total mirror exposure than Alo in Experiment 1. Second, his habituation data suggested that he was still somewhat fearful of the box. Third, a large number of discrimination trials might allow us to observe a learning curve if he was still gaining information about mirrors and boxes. Fourth, because Kyaaro quickly habituated to negative reinforcers on the first round of test trials (as discussed later), we administered a second round. The second round was a subset of the overall trials, 73 positive and 47 negative, that occurred between January 1993 and June 1993. All these trials were performed "blind." We determined the frequency of Kyaaro's negative versus positive trials by a coin flip.

Detour trials. Placement of the mirror against the wall at an angle did not prevent (see Table 1) but might have discouraged our subjects from searching behind the mirror. Search behavior is common in children up to 10 months old (Baudonniere, 1993; Zazzo, 1975) and possibly up to 22 months of age (Loveland, 1987). To team whether our parrots would search if given a better opportunity and despite additional 
mirror experience, we ran trials (a) by placing the mirror, supported by plexiglass, in the center of the counter and (b) 6 months after completion of the mirror-mediated spatial locating experiments described below. Behind-the-mirror searches at this point would call into question the hierarchical nature of the cognitive capacities proposed as necessary for success on different types of mirror tasks. We ran a full set of trials only with Kyaaro (see footnote 3 ).

"Clear" trials. These tests would determine whether Kyaaro indeed differentiated reflected from nonreflected information. Two-year-old children cannot: Although they locate reflected objects without using knowledge of their self-image (Robinson, Connell, McKenzie, \& Day, 1990), they cannot distinguish between seeing themselves in a mirror and seeing a twin behind a glass plate (Zazzo, 1975, 1979). The twin task demonstrated that the children not only failed at self-recognition but also that they did not understand that the mirror reflected information on their side of the frame and that glass transmitted information from the other side (Loveland, 1987).

We could not replicate the twin task but could examine whether the ability being tested-that of differentiating between reflected and nonreflected information-was present in a parrot. Thus we interspersed detour trials randomly with "clear" trials. In clear trials, we placed identical boxes behind and in front of an empty frame; each box contained either a positive or negative item. We used an empty frame because we could not obtain completely nonreflective glass. A bird that walked around or through the frame to obtain a positive object and ignored the box facing the frame would show it knew whether it was receiving reflected or nonreflected information. We ran trials with a negative object behind the frame and a positive item in front to test whether the bird had simply learned to walk around the frame. To learn whether Kyaaro would "spook" at the novel apparatus, we gave him one pretrial with an empty frame and a single object placed behind it prior to the actual tests.

\section{Results}

Alo

Habituation trials. Alo searched the box in 18 of 22 trials whether or not pasta was present (i.e., searched on 9 "go" and 9 "no-go" trials). The 4 trials in which she did not search occurred in the first 7 trials. She then chewed on and looked in the box on every trial. Her latency of approach also decreased as the experiment progressed: Her approach took 5 min on Trial 1, but only 1 min on Trial 5 ; by Trial 12, she approached the box in 3-8 s.

Test trials. Ala used the mirror to distinguish items. When the observer baited the box, she looked in the box after viewing the mirror image in 18 of 20 positive trials and retreated on 16 of 20 negative trials. In blind tests, her score for parallel mirror trials was 19 of 20 for positive trials and 18 of 20 for negative trials; for trials with the box angled to the mirror, her positive and negative scores, respectively, were 20 of 20 and 19 of 20. In all positive tests, she immediately walked to the box and retrieved the pasta; she never tapped at the mirror nor approached the mirror more closely than the box. In tests for difference in proportions at the .05 confidence level, her scores are not significantly different for blind and regular trials and parallel versus angled presentations on, respectively, negative and positive trials. We therefore lumped all data (57 of 60 responses appropriate for positive reward, 53 of 60 responses appropriate for negative stimuli) for chi-square tests. Alo's results were significant at the $p<.0001$ level, $x^{2}(1, N=120)=$ 80.23. When we used novel objects (toys instead of pasta for positive stimuli and novel plastic animals as negative stimuli), she responded equally well: She retrieved the objects on 5 of 5 positive trials and walked away on 5 of 5 negative trials (binomial test, chance of $.5, p=.001$ ). 
Figure 2. Kyaaro's habituation to negative stimuli. After 15 to 20 exposures to the originally negative items, Kyaaro began not merely to habituate, but to treat them as positive rewards.

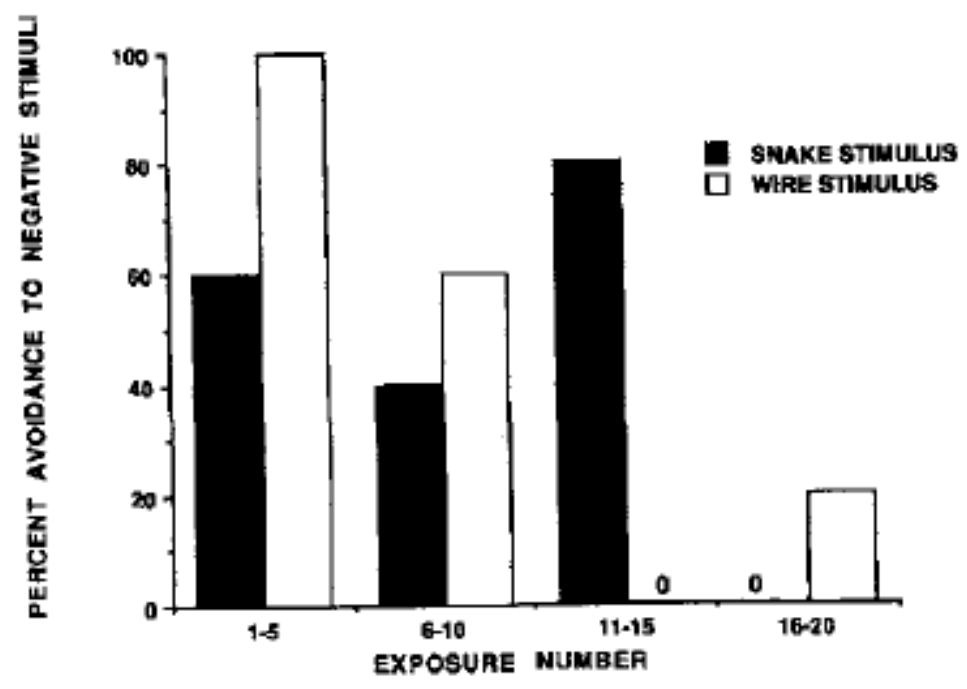

Kyaaro

Habituation trials. Kyaaro searched the box in 10 of 20 trials, but his behavior was not correlated with the presence of pasta. He did, however, look in the box on 5 of his final 6 "go" trials.

First-round test trials. Kyaaro at first did not appear to succeed in this task. He looked in the box on 60 of 70 positive trials but retreated on only 24 of 58 negative trials. His data and behavior suggested, however, that he not only had habituated to the objects used as negative stimuli (Figure 2) but actually learned to treat them as positive rewards. A binomial test showed that, overall, he approached these objects more often than by chance $(p=.044)$. When we reevaluated his data, basing our statistics only on the first 10 exposures to each positive and negative stimulus (40 trials total), his performance was significant, $X^{2}(1, N$ $=40)=8.29, p<.004$.

Second-round test trials. With a towel as the consistent negative stimulus, Kyaaro used the mirror to distinguish items. He looked in the box after viewing the mirror image in 59 of 73 positive trials and retreated on 40 of 47 negative trials. His results were significant at the $p<.0001$ level, $x^{2}(1, N=120)=$ 50.21. He was also correct on all five trials that used novel positive stimuli.

"Clear" trials. In the habituation trial with an empty frame with a positive object behind it, Kyaaro did not immediately walk around or through the frame. He glanced at the place where the object would have been hidden in mirror trials several times before he walked through the frame to obtain the desirable object.

On 29 of 30 formal trials (14 positive in front/negative in back; 15 negative in front/positive in back), he consistently obtained the positive reward, either by going to the box in front of the frame or walking around to the box in back. On one trial (midway through the series), he did not approach the apparatus and appeared scared of the negative object behind the frame. His results were significant at the $p<.0001$ level, $X^{2}(2, N=30)=30.00$.

Detour trials. On only 2 of 33 detour trials ${ }^{6}$ did Kyaaro react incorrectly. He once looked in the near box that held a negative stimulus and once walked around the apparatus to recover a negative stimulus. He 
appropriately retreated on 14 trials and looked in the box in 17 trials. His results were significant at the $p<$ .0001 level, $X^{2}(2, N=33)=29.22$.

\section{Discussion}

During habituation trials, both birds learned not to fear the box. Though the data suggest that, unlike monkeys (Itakura, 1987), they did not learn about mirror use, other interpretations are possible. For Alo, interaction with the box became a reward: In 13 of 22 trials, she approached the box without looking at the mirror. Too, although Kyaaro's overall score was at the level of chance, scores on his last 6 positive trials suggest he learned that the box could be a source of reward.

These interpretations appear justified given the birds' performance on test trials. Alo avoided the box on most negative trials and approached on most positive trials. Kyaaro's data were clearly affected by his habituation to the negative stimuli. When tests were rerun with a small towel (which was associated with strongly aversive medical treatment), his level of accuracy matched Ala's. The mirror, therefore, was not simply a cue to begin a search, but a tool that provided search information. Because there was no difference on either of the birds' scores on blind trials versus those with knowledgeable observers, they worked on the basis of what they saw in the mirror and not on external cues provided by humans.

According to Gallup (1982), one criterion for determining whether an animal processes mirror information to respond to objects is that it "respond appropriately by turning away from the mirror to gain more direct access to the object of the reflection" (p. 240; see also Robinson et a!., 1990). Unfortunately, we cannot test whether a parrot would, for example, turn away from a mirror to obtain an object placed directly behind it: The position of parrots' eyes would afford a simultaneous view of the mirror reflection and the object. A parrot will, however, walk around the edge of a box angled to, and thus somewhat away from, the mirror to obtain the hidden reward. Responses did not differ from trials in which the box was parallel to the mirror. In both situations, after looking in the mirror from behind the box, a bird walked directly to the box on positive trials: It never avoided the box, dithered between the image and the object, or attempted to retrieve the mirror image.

In most mirror-mediated discrimination experiments (e.g., Itaknra, 1987; Menzel et a!., 1985), animals are repeatedly tested with a single set of positive and negative stimuli. Subjects may thereby respond using an associative process (i.e., learn that one type of mirror cue leads to something positive and another to something negative, without necessarily recognizing that mirror information is about specific items). Both birds, however, responded appropriately on all trials in which we hid novel stimuli. Such data suggest they were processing the information specifically rather than generally.

Kyaaro's reactions on detour and clear trials suggested that he differentiated reflected and nonreflected information. His inappropriate behavior on a detour trial that had a negative stimulus in front of the mirror was intriguing. He viewed the reflection of the negative item, backed off sideways (parallel to the mirror), stopped at the edge of the mirror, and peered behind it. Interestingly, this trial occurred after several clear trials in which walking around the frame had led to a reward. In clear trials, however, he did not examine the apparatus and then sidle off; rather he detoured around the frame if such behavior was appropriate. Whether in this detour trial he was checking for hidden rewards is unclear, but his behavior was different from previous or subsequent trials. For all detour versus clear trials, Kyaaro, like children, need not have used presence or absence of his reflection as a cue (see Robinson et al., 1990), because the procedure also tested whether he could use visual information (i.e., process the difference between reflected and real information) about his surroundings. The data demonstrate that he did not respond to the apparatus in a rote manner. 
In sum, the data suggest that Grey parrots can perform mirror-mediated object discrimination. They avoided negative items and approached positive items on the basis of mirror information. They responded as appropriately to novel as to familiar stimuli. They responded without verbal prompts, such as those given to children, to find the object or attend to the mirror (Robinson et al., 1990). One might nevertheless argue that the mirror was irrelevant: The birds checked the box unless frightened by the vision of negative stimuli; they need not have realized they were seeing an image of the contents of the box. This explanation cannot be entirely discounted. However, had the birds simply reacted to the presence or absence of fear, they would have always retreated on negative trials and not have made any errors. Kyaaro's reactions during clear trials also suggest, although cannot prove, that he understood the concept of an image versus an object. When the negative item was in view behind the frame, he explored the positive box in front and did not simply move away. Moreover, because Kyaaro was correct on all but one trial, and this error occurred in the middle of the series, he did not simply learn an association between presence versus absence of a mirror and an appropriate action. In some sense, however, such discussion is irrelevant, because a mirror-mediated discrimination task is not designed to test whether subjects realize that they are seeing a representation, but only whether an image provides the same source of information as the object itself (i.e., if the subject correlates the object and its image). On those grounds, we suggest that the parrots did indeed perform mirror-mediated object discriminations.

\section{Experiment 3. Mirror-Mediated Spatial Locating}

Mirror-mediated spatial locating requires use of a mirror to choose between possible locations of hidden objects. The task, unlike mirror-guided reaching, does not require moment-to-moment information processing to provide feedback about the status of the search but is more complicated than a mirrortriggered search, in which a mirror is merely a cue to begin exploring areas likely to provide rewards. In mirror-mediated spatial locating, a subject must use information contained in the reflected image to choose which of several, often contiguous, areas is correct. Thus, a subject must understand the correspondence between the location of the object in real space and the information in the reflection (Povinelli, 1989); i.e., use a spatial representation to solve the problem. Such a task thus requires a higher order of information processing than does mirror-mediated discrimination. Japanese monkeys, for example, have learned this ability (Itakura, 1987), but no comparable data exist for birds. Our birds' success on mirror-mediated object discrimination, which showed that they could go beyond mirrortriggered searches, suggested that Grey parrots would be good candidates for testing mirror-mediated spatial locating.

\section{Method}

\section{Subjects and Housing}

The subjects and their housing were the same as in Experiment 1.

\section{Apparatus and Procedure. Part 1}

We used the mirror from Experiment 1 and a drawer underneath the countertop. Pieces of posterboard divided the overhang of the countertop above the drawer into three $17 \mathrm{-cm}$ spaces: A, B, and C (Figure 3). Edges of the posterboard dividers were flush with the underside of the countertop. A parrot looking into one section could not see into the others. The mirror reflected the entire underside of the counter; a "lip" on this underside was a further precaution against inadvertent cues. Additional trials tested whether birds could find a reward in the absence of mirror cues.

As in Experiment 2, birds had habituation and test trials. To begin a trial, we placed a bird where it could not sec the counter while a trainer baited one of the three sections and covered the apparatus with 
cardboard. The choice of position was randomized, but no position was used more than twice in a row. In habituation and a portion of the test trials (1/3 for Alo and 1/2 for Kyaaro), the observer was the baiter; in blind trials, the observer did not know which section was baited. In both cases, the observer, looking at the bird and not the apparatus, then placed the bird at a standard position $50 \mathrm{~cm}$ from the edge of the counter and removed the cardboard that covered the apparatus. The parrot could not see the bait without looking in the mirror or under the counter.

Figure 3. Apparatus for mirror-mediated spatial locating procedure for both birds.

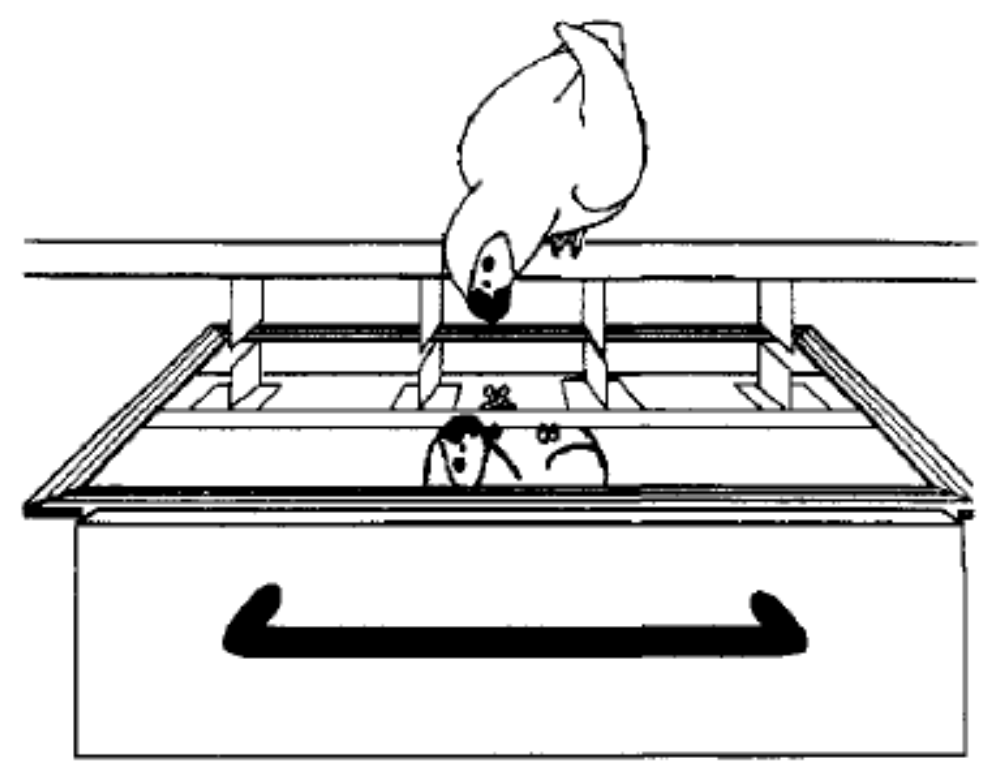

During habituation trials, which were learning trials, birds could search until they found the bait (pasta). Initially, no barriers divided the counter; habituation ended when a bird used the mirror to view the underside of the counter to find the pasta or after 20 attempts, whichever came first. Birds were habituated to dividers in 20 subsequent trials or when they began to use the mirror, whichever came first.

After habituation, a parrot had only one chance to use the mirror to locate the pasta; a trial ended with the first movement of its head into A, B, or C after it had scanned the mirror. Alo received 5 trials per week for a total of 62 blind and 30 observer-baited trials from November 1992 to June 1993; Kyaaro received 15 trials per week for a total of 60 blind and 60 observer-baited trials from June to August $1993 .{ }^{7}$

\section{Apparatus and Procedure. Part 2}

To show mastery of mirror-mediated spatial locating, a subject must use a mirror to find objects hidden in novel positions. We therefore devised two sets of novel trials. In the first set, we simply modified Part 1 by dividing the ledge into four rather than three compartments. The under-the-counter location remained constant, but its spatial configuration was altered. Because Kyaaro had a position preference (discussed later), we gave him an additional series of tests before advancing to the next set of trials: We backtracked to the three-position task, placing negative stimuli in two compartments and a positive item in the third, and then repeated the experiment with four compartments. In the second set of novel trials, mirrors reflected information from above rather than below a barrier that encircled one wall and part of another (Figure 4). We divided the ledge into eight sections, each $17 \mathrm{~cm}$; the reward-pasta-was hidden randomly among these sections. We also included trials in which rewards were present (a) without mirrors, (b) with 
covered mirrors, and (c) were not reflected in the mirror. In all trials in Part 2 the observer was unaware of the location of the pasta.

Figure 4. Apparatus for mirror-mediated spatial locating transfer procedure for Alo.

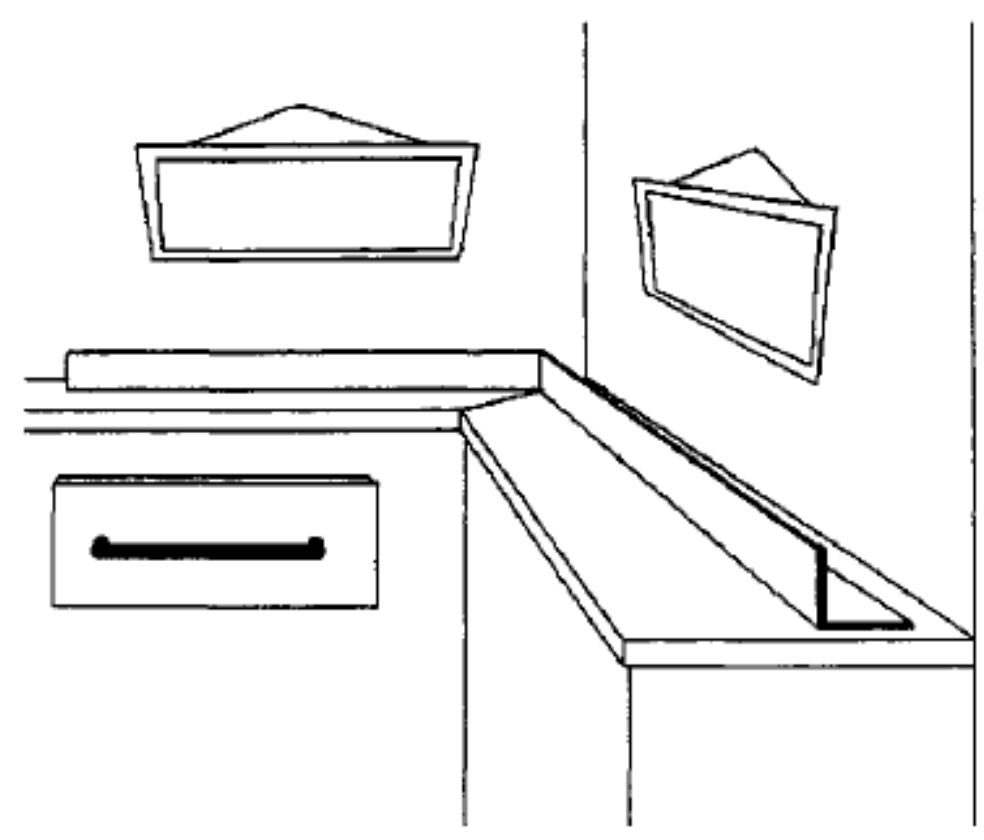

\section{Results}

\section{Habituation Trials}

Both birds habituated quickly. On the first two trials without dividers, Alo attended to her reflection more than the pasta; she retrieved the pasta on her next trial. Kyaaro ignored the pasta on his first trial but found it on the second. Both birds were also initially more interested in chewing the dividers than the pasta. After six trials in which Ala had chewed the dividers, we placed a presumed negative stimulus in one section and the pasta in another. She retrieved the negative stimulus and then began to attend to the mirror cues. Kyaaro was dissuaded from chewing by hearing "No." In his first six trials (pasta twice in each location). He searched each of the partitions in order ( $A, B, C)$ until he located the pasta. When given only one chance to find the pasta on the next six trials (pasta twice in each location), he began to use the mirror rather than search in order. Ala had a total of 12 habituation trials; Kyaaro had 14.

\section{Test Trials. Part 1}

Both birds' data from blind and observer-baited trials (54 of 62 correct and 24 of 30 trials correct for Alo; 48 of 60 correct and 44 of 60 correct for Kyaaro) were not significantly different at the .05 level on a test for difference in proportions, so for each bird we combined blind and observer-baited trials for statistical analysis. All of Kyaaro's observer-baited trials preceded his blind trials; the data thus showed that his accuracy was not based on human cues or experience.

Alo's overall performance, $84.8 \%$ correct, was significant for each site (Table 2; binomial test. chance = 1/3). $p<.0001$. Although she appeared somewhat biased toward Site B (Table 2), a test on her distribution of errors showed that this bias was not statistically significant, $X^{2}(2, N=14)=2.090, p=$ 
.3516. Most errors occurred at the beginning of testing and after a 3-week hiatus in testing during a vacation and intersession break (Figure 5).

Kyaaro's overall performance. $76.6 \%$ correct, was also significant for each site (Table 3; binomial test, chance of $1 / 3, p \leq .006$ ). Kyaaro, however, had a clear position preference (Table 3 ). His distribution of errors was significantly different from chance, $X^{2}(4, N=28)=17.63 . p=.0015$. He would look in the mirror in order, $A \rightarrow B \rightarrow C$, and if the reward was not in $A$, often chose $B$ before looking in all three areas. Such behavior led him to be least correct when a reward was in $\mathrm{C}$.

Table 2. Ala's Position Preferences in Mirror-Mediated Searches

\begin{tabular}{|cccc|}
\hline & \multicolumn{3}{c|}{ No. of times Alo chose each site } \\
\cline { 2 - 4 } Pasta location & A & B & C \\
\hline A & 24 & 7 & 1 \\
B & 0 & 30 & 0 \\
C & 1 & 5 & 24 \\
\hline
\end{tabular}

\section{Trials Without Mirror Cues}

Neither bird succeeded when we covered the mirror with cardboard. On their first trials, Alo failed to find the pasta, and Kyaaro refused to search. On subsequent trials with a covered mirror, Alo refused to look in the apparatus; she looked at the cardboard and moved away. In subsequent trials Kyaaro either refused to search or went directly to Site A, whether or not pasta was there.

Test Trials in Novel Positions. Part 2

Four positions. Both birds succeeded in choosing among four sites. Alo was correct on six of eight trials, including the first trial. Her results were significant (binomial test, chance of $1 / 4, p=.0038$ ). Kyaaro was correct on five of eight trials, including his first three trials. His results were significant (binomial test, chance of $1 / 4, p=.0231$ ), but he consistently erred on end sites: both times on A and once on $D$. Both birds thus adapted to minimal novelty, but Kyaaro favored middle positions.

Kyaaro's position problems declined after we returned to the three-position task and gave him six trials that encouraged him to look carefully in all sections. In these trials we placed moderately negative stimuli in two sites and pasta in a third; Kyaaro avoided negative items (rubber animals) on the first three trials and then chose (and played with) one of these objects on subsequent trials. When four compartments were reintroduced, he was correct on six of eight trials, with one error in A and one in B. His results were again significant (binomial test, chance of $1 / 4, p=.0038$ ).

Overhead mirror. On novel placement trials in which she had to look above a shelf, Alo responded appropriately. She did not find the reward when the mirror was covered (4 trials). When pasta was placed in an area not reflected in the mirror (4 trials), she checked the mirror but did not search. On eight trials when both pasta and mirror cues were present, she was correct on six trials. Her scores were significant at the .008 level, $X^{2}(2, N=16)=9.6$. She also had three mistrials. Once, she used the mirror to search correctly, but the pasta was placed too far back for her physically to obtain it. In two other mistrials, she could see pasta reflected indirectly by the mirror placed at right angles to the hiding spot; she searched near the correct site but could not be expected to search appropriately. We reran additional trials with a covered mirror at the end of the experiment to ensure that the test situation had not become a cue to search: Alo scanned the area, then proceeded to preen. 
We could not perform transfer trials with mirrors above Kyaaro's head. Even after several weeks of habituation, he remained frightened of the apparatus. He would either cower in a comer or jump off the laboratory bench.

Figure 5. Alo's learning curve for mirror-mediated spatial locating. Her performance improved until she reached $100 \%$ accuracy, although her accuracy then decreased somewhat. Following a subsequent 3-week break in testing, her performance deteriorated (Trials 16-18) before returning to $100 \%$ accuracy.

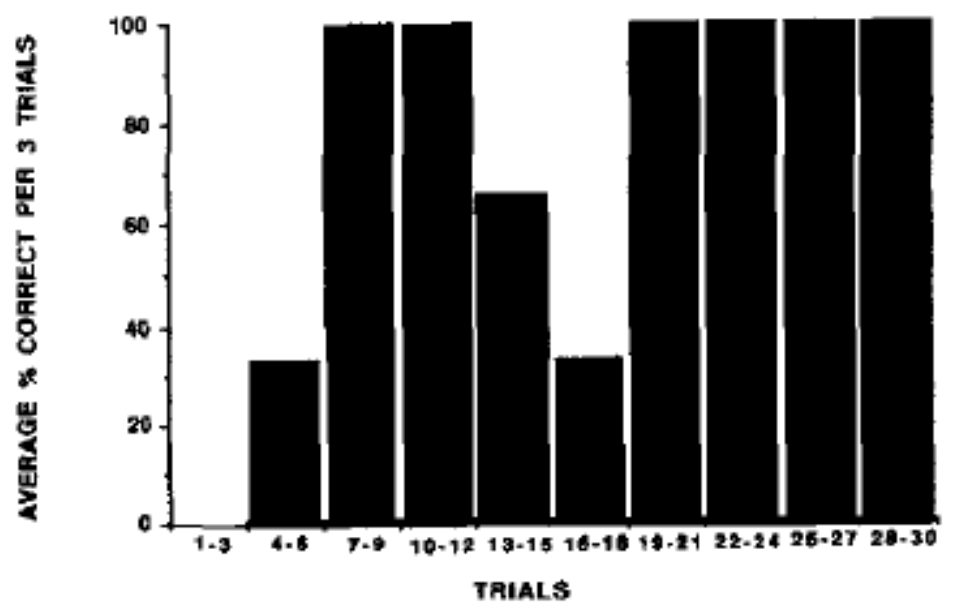

\section{Discussion}

Both birds used a mirror to locate hidden rewards, even in novel locations. After habituation trials, they never attended to their own reflections, dithered between the image and the object, nor attempted to retrieve the mirror image. They were also unable to find the objects in the absence of a mirror. Their behavior, however, did differ in some ways.

Ala's data suggest that she learned to use a mirror to access the rewarded location. In tests with three choices, her accuracy increased rapidly with the number of trials and remained fairly constant until a period in which she received no trials. Her subsequent decrease in accuracy and recovery after additional trials suggest that she might have temporarily forgotten how to perform the task.

She did, however, transfer to modified conditions on the very first trials. She maintained her accuracy when faced with four, rather than three, possible sites. This task represented only a small change, but the data suggest that she had not simply learned a rote behavior. Such a conclusion is supported by her accuracy on the task in which she had to look above, rather than below, to obtain her reward.

Kyaaro's data were statistically significant on the three-and four-position tasks, but he did exhibit position preferences. His behavior with respect to end sites is like that of "attention-deficit disordered" (ADD) children (Barkley, 1990). Given match-to-sample tasks with linearly arranged choices, ADD children preferentially choose middle objects; if, however, choice objects are arranged in a triangle, ADD children choose appropriately (D. Sherman, personal communication, February, 1994\}. Thus, ADD children look straight ahead, ignoring end positions. Although Kyaaro first looked at an end in the mirror, possibly because of his eye placement, he often chose middle positions. Note that he exhibits other ADD-like behavior (Barkley, 1990; Pepperberg, 1994b\}. For example, his accuracy improves when "activities ... involve an immediate consequence for completing them" (Barkley, 1990, p. 2). Thus, after experiencing trials that provided greater incentives to attend to mirror cues about all possible compartments (i.e., 
negative items in some sites), his pattern of errors changed. His improvement was not likely a consequence of having more trials, as his position preference did not alter with trial number during the original three-position task.

Table 3. Kyaaro 's Position Preferences in Mirror-Mediated Searches

\begin{tabular}{|cccc|}
\hline & \multicolumn{3}{c|}{ No. of times Kyaaro chose each site } \\
\cline { 2 - 5 } Pasta location & A & B & C \\
\hline A & 38 & 1 & 1 \\
B & 6 & 33 & 1 \\
C & 5 & 14 & 21 \\
\hline
\end{tabular}

Whether ADD caused Kyaaro's inability to habituate to the overhead apparatus is unclear. He did not, however, fail because of an inability to use a mirror. We have yet to devise an equivalent transfer situation to which he will habituate.

We note that according to some researchers (Anderson, 1986; Povinelli, 1989) the data just discussed are evidence for visio-spatial problem-solving skills. The birds' refusals to search in the mirror's absence could, however, suggest that (a) a mirror had become a cue to search or (b) they recognized that a search in the mirror's absence was useless. In the first case, a bird is simply associating events; in the second case, it is engaged in information processing. The data do not conclusively support the latter interpretation, but the birds' successes on mirror-mediated object discrimination tasks, both before and, for Kyaaro, after spatial locating, suggest that a mirror was not simply a trigger to search. Here they did not interact with their mirror image, but immediately obtained pasta; thus they did not succeed merely because they happened to see the pasta while interacting with their image. They responded at a level of accuracy not unlike that of 3-year-old children but without the verbal and physical prompts children receive to attend to the apparatus (Field \& Hogg, 1992). In sum, the data suggest that the subjects do indeed understand that the mirror provides a representation (i.e., understand the basic function of the mirror and are not merely engaged in mirror-triggered search).

\section{General Discussion}

Two Grey parrots engaged in mirror-image stimulation, mirror-mediated object discrimination, and mirrormediated spatial locating. While viewing their mirror images, they exhibited behavior patterns similar to those of marmosets, monkeys, very young children ( $<18$ months $\}$, and the initial responses of orangutans and young chimpanzees. In object discrimination and spatial locating tasks, Grey parrots used mirrors to discriminate among exemplars and locate hidden objects. Even Kyaaro, who exhibited certain position preferences (possibly a consequence of an attention deficit disorder), performed at a statistically significant level. The parrots' transfers to novel situations show that they were not simply engaging in mirror-triggered search. These birds are the first nonmammalian subjects to use mirrors successfully in both these tasks; they performed at levels similar to those of monkeys (Itakura, 1987) and 2-year-old children (Robinson et al., 1990) on discrimination tasks and to 3-year-old children (Field \& Hogg, 1992) and possibly elephants (Povinelli, 1989\} on locating tasks. Overall, the data suggest that Grey parrots can indeed process mirror information: They differentiate reflective versus nonreflective information and use a representation to locate hidden objects.

Whether Grey parrots will ultimately succeed on more complex mirror tasks (mirror-guided reaching, mark tests) remains to be seen. Unfortunately, we cannot easily administer the same mark test or guided reaching tasks that have been used with apes and monkeys: Grey parrots, unlike apes and monkeys, do 
not often use their feet either to explore their bodies or to investigate items. As in research with dolphins (Marino et al., 1994), our work must therefore focus on conceptual rather than technical similarities in tests among species.

The mark test is likely to prove particularly difficult to administer. Although parrots use visual information to identify objects (e.g., Pepperherg, 1983, 1990a, 1992) and at least one psittacid--the budgerigar (Melopsittacus undulates)---uses visual information to recognize conspecifics (Brown \& Dooling, 1993; Trillmich, 1976), we have only limited evidence to suggest that a parrot will attend to an unusual mark either on itself or a conspecific companion. We are, however, examining how preening behavior might be used to develop mark tests.

Because parrots lack many (but not all) the behavior patterns associated with forearms and hands in apes and monkeys, mirror-guided reaching tasks also must be adapted to psittacine anatomy. We are thus examining whether parrots can solve patterned string problems (e.g., Ducker \& Rensch, 1976), which could be adapted for monitoring their progress in a mirror (see Brown, McDowell, \& Robinson, 1965, for a similar study with monkeys). Only then will we learn whether an avian species possesses complex visio-spatial problem-solving abilities analogous to those of mammals.

The question will, however, always be whether adapted tests truly replicate those presented to other species (see Eglash \& Snowdon, 1983; Marino et al., 1994; Pepperberg \& Kozak, 1986). Like studies of language- and counting-like behavior in animals (e.g., Pepperberg, 1994a), studies of mirror use can always be interpreted in ways that emphasize differences rather than similarities in, or continuities among, species (e.g., Heyes, 1994). Whatever the interpretations, cross-species data, such as those obtained here, provide critical information about cognitive abilities present or absent in nonhumans.

\section{Notes}

${ }^{1}$ Note, however, that Amsterdam's (1972) experiments to examine self-awareness in children lacked many of the controls used by Gallup (1970) in his animal studies (see Gallup \& Povinelli, 1993). Thus only her observations, but not her conclusions, can be compared directly with the animal data.

${ }^{2}$ Epstein, Lanza, and Skinner (1981) purported to study self-awareness in the pigeon; their project, however, merely demonstrated that subjects could be taught to peck at a specific target observed in a mirror. Whether the pigeons understood the correlation between the image in the mirror and themselves was not proven. See Gallup and Suarez (1986) for a detailed critique and citation of a report that failed to replicate the Epstein et al. study.

${ }^{3}$ During the period in which we were running all our experiments, both birds-but particularly Kyaaro--often split the skin on their breast bone during clumsy landings. These mishaps required surgical repair, and the birds subsequently wore plastic "Elizabethan" collars for 1 to 3 weeks to keep them from tearing at the stitches. These collars restricted their maneuverability and mobility and thus prevented tests of mirror use. Moreover, after each surgery, Alo became more difficult to handle and eventually could not be handled by the students who were performing the tests. During these studies, both birds were also diagnosed as having psittacosis; treatment involved weekly $1.6 \mathrm{cc}$ intramuscular shots. Birds were lethargic for $24 \mathrm{hr}$ after a shot.

${ }^{4}$ We used horizontal presentations to see whether the birds would react at all. We did not continue with such trials to avoid training the birds on horizontal presentations before testing their ability to use a horizontal mirror to locate objects. 
${ }^{5}$ We used a go/no-go procedure for habituation rather than positive-negative stimuli for two reasons. First, our parrots tend to be neophobic (Pepperberg, 1987), and any negative stimuli might have prevented their habituation. Second, switching to positive-negative trials without training provided a way to separate habituation and test trials.

${ }^{6}$ Our protocol called for 30 trials, but 3 additional trials were done by mistake.

${ }^{7}$ The different procedures reflected the schedule of the students assigned to each bird. Our protocol called for 60 blind trials for Alo, but 2 additional trials were done by mistake. Because Kyaaro's results in Experiment 2 were affected by the number of trials he received, we ran 30 additional trials to see whether his results would similarly be affected in Experiment 3.

\section{References}

Amsterdam, B. (1972). Mirror self-image reactions before age two. Developmental Psychobiology, 5, 297305.

Anderson, J. R. (1984). Monkeys with mirrors: Some questions for primate psychology. Journal of Primatologv, 5, 81-89.

Anderson, J. R. (1986). Mirror-mediated finding of hidden food by monkeys (Macaca tonkeana and $M$. fascicularis). Journal of Comparative Psychology, 100, 237-242.

Anderson, J. R. (1993). To see ourselves as others see us-A response. New Ideas in Psychology, 11, 339-346.

Anderson, J. R., \& Bayart, F. (1985). Les effets du miroir sur le comportement de macaques: Habituation, 6 vitement et facilitation sociale. (The effects of a mirror on the behavior of rnacaques: Habituation, avoidance and social facilitation.) Biology of Behavior, 10, 159-167.

Andrews, E. (1966). Slate-Colored Junco responds to mirror. Bird Banding, 37, 206.

Barkley, R. A. (1990). Attention deficit disorder: A handbook for diagnosis and treatment. New York: Guildford Press.

Baudonniere, P.M. (1993, October). Emergence of the symbolic function and modifications of communicative skills in young children. Paper presented at the Jacques Monad Conference Aussois, France.

Brooks-Gunn, J., \& Lewis, M. (1984). The development of earlv visual self-recognition. Developmental Review, 4, 215-239. .

Brown, S., \& Dooling, R. J. (1993). Perception of conspecific faces by budgerigars (Melopsittacus undulatus): II. Synthetic models. Journal of Comparative Psychology, 107, 48-60.

Brown, W. L., McDowell, A. A., \& Robinson, E. M. (1965). Discrimination learning of mirrored cues by rhesus monkeys. Journal of Genetic Psychology, 106, 123-128.

Censky, E. J., \& Ficken, M.S. (1982). Responses of Black-capped Chickadees to mirrors. Wilson's Bulletin, 94, 590-594.

Delsaut, M., \& Roy, J. C. (1980). Auditory and visual stimuli as reinforcers among lovebirds (Agapornis roseicollis). Behavioral and Neural Biology, 28, 319-334.

Diamond, J., \& Bond, A (1989). Note on the lasting responsiveness of a kea Nestor notabilis towards its mirror image. Aviculture Magazine, 95, 92-94.

Diamond, J., \& Bond, A. (1991). Social behavior and the ontogeny of foraging in the Kea (Nestor notabilis). Ethology, 88, 128-144.

Dixon, J. C. (1957). Development of self-recognition. Journal of Genetic Psychology, 91, 251-256.

Ducker, G., \& Rensch, B. (1976). The solution of patterned string problems by hirds. Behaviour, 62, 164173. 
Eglash, A R., \& Snowdon, C. T. (1983). Mirror-image responses in pygmy marmosets (Cebuella pygmaea). American Journal of Primatology, 5, 211-219.

Epstein, R., Lanza, R. P., \& Skinner, B. F. (1981). "Self-awareness" in the pigeon. Science, 212, 695-696.

Field, J., \& Hogg, V. (1992). Young children's ability to find objects reflected in mirrors. Australian Journal of Psychology, 44, 9-11.

Gallup, G. G., Jr. (1968). Mirror-image stimulation. Psychological Bulletin, 70, 782-793.

Gallup, G. G., Jr. (1970). Chimpanzees: Self-recognition. Science, 167, 86-87.

Gallup, G. G., Jr. (1982). Self-awareness and the emergence of mind in primates. American Journal of Primatology 2, 237-248.

Gallup, G. G., Jr. (1987). Self-awareness. Comparative Primate Behavior, 2B, 3-16.

Gallup, G. G., Jr. (1991). Toward a comparative psychology of self-awareness: Species limitations and cognitive consequences. In J. Strauss \& G. R. Goethals (Eds.), The self: Interdisciplinary approaches (pp. 121-135). New York: Springer-Verlag.

Gallup, G. G .. Jr., \& Capper, S. A. (1970). Preference for mirror-image stimulation in finches (Passer domesticus domesticus) and parakeets (Melopsittacus undulatus). Animal Behaviour, 18 621624.

Gallup, G. G., Jr., \& Povinelli, D. J. (1993). Mirror, mirror on the wall, which is the most heuristic theory of them all? A response to Mitchell. New Ideas in Psychology, 11, 327-335.

Gallup, G. G., Jr., \& Suarez, S.D. (1986). Self-awareness and the emergence of mind in humans and other primates. In J. Suls \& A. Greenwald (Eds.), Psychological perspectives on the self (Vol. 3, pp. 3-26). Hillsdale, NJ: Erlbaum.

Gnam, R. (1988). Preliminary results on the breeding biology of the Bahama Amazon. Parrot Letter, 1, 21-26.

Hall. K. R. L. (1962). Behaviour of monkeys towards mirror images. Nature, London, 196, 1258-1261.

Heyes, C. M. (1994). Reflections on self-recognition in primates. Animal Behaviour, 147, 909-919.

Itakura, S. (1987). Mirror guided behavior in Japanese monkeys (Macaca fuscata fuscata). Primates, 28, 149-161.

Lin, A. C., Bard, K. A., \& Anderson, J. R. (1992). Development of self-recognition in chimpanzees (Pan troglodytes). Journal of Comparative Psychology, 106, 120-127.

Lohmann, A., Delius, J.D., Hollard, V. D., \& Friesel, M. F. (1988). Discrimination of shape reflections and shape orientation by Columba livia. Journal of Comparative Psychology, 102, 3-13.

Loveland, K. A. (1987). Behavior of young children with Down syndrome before the mirror: Finding things reflected. Child Development, 58, 928-936.

Marchal, P., \& Anderson, J. R. (1993). Mirror-image responses in capuchin monkeys (Cebus capucinus): Social responses and use of reflected environmental information. Folia Primatologica, 61, 165173.

Marino, L., Reiss, D., \& Gallup, G. G., Jr. (1994). Mirror self-recognition in bottle-nosed dolphins: Implications for comparative investigations of highly dissimilar species. In S. Parker, R. Mitchell, \& M. Boccia (Eds.), Self-awareness in humans and nonhumans (pp. 380-391). Cambridge, England: Cambridge University Press.

Mebcs, H. D. (1978). Pair-specific duetting in the peach-faced lovebird (Agapornis roseicollis). Naturwissenschaften, 65, 66-67.

Menzel, E. W., Jr., Savage-Rumbaugh, E. S., \& Lawson, J. (1985). Chimpanzee (Pan troglodytes) spatial problem solving with the use of mirrors and televised equivalents of mirrors. Journal of Comparative Psychology, 99, 211-217.

Mitchell, R. W. (1993). Mental models of mirror self-recognition: Two theories. New Ideas in Psychology, 11, 295-325.

Moody, M. F. (1975). Perception of total reflection in Barbus. Behavioral Biology, 15, 239-243. 
Pepperberg, I. M. (1983). Cognition in the African Grey parrot: Preliminary evidence for auditory/vocal comprehension of the class concept. Animal Learning \& Behavior, 11, 179-185.

Pepperberg, I. M. (1987). Evidence for conceptual quantitative abilities in the African Grey parrot: Labeling of cardinal sets. Ethology, 75, 37-61.

Pepperberg, I. M. (1990a). Cognition in an African Grey parrot (Psittacus erithacus): Further evidence for comprehension of categories and labels. Journal of Comparative Psychology, 104, 41-52.

Pepperberg, I. M. (1990b). Referential mapping: A technique for attaching functional significance to the innovative utterances of an African Grey parrot (Psittacus erithacu.s). Applied Psycholinguistics, 11, 23-44.

Pepperberg, I. M. (1990c). Some cognitive capacities of an African Grey parrot. In P. J. B. Slater, J. S. Rosenblatt, \& C. Beer (Eds.), Advances in the study of behavior (Vol. 19, pp. 357-409). New York: Academic Press.

Pepperberg, I. M. (1992). Proficient performance of a conjunctive, recursive task by an African Grey parrot (Psittacus erithacus). Journal of Comparative Psychology, 106, 295-305.

Pepperberg, I. M. (1993). A review of the effects of social interaction on vocal learning in African Grey parrots (Psittacus erithacus). Netherlands Journal of Zoology, 43, 104-124.

Pepperberg, I. M. (1994a). Numerical competence in an African Grey parrot (Psittacus erithacus). Journal of Comparative Psychology, 108, 1-9.

Pepperberg, I. M. (1994b). Vocal learning in Grey parrots (Psittacus erithacus). Auk, 111, 300-313.

Pepperberg, I. M., Brese, K. J., \& Harris, B. J. (1991). Solitary sound play during acquisition of English vocalizations by an African Grey parrot (Psittacus erithacus); Possible parallels with children's monologue speech. Applied Psycholinguistics, 12, 151-178.

Pepperberg, I. M., \& Brezinsky, M. (1991). Acquisition of a relative class concept by an African Grey parrot (Psittacus erithacus): Discriminations based on relative size. Journal of Comparative Psychology, 105, 286-294.

Pepperberg, I. M., \& Kozak, F. A. (1986). Object permanence in the African Grey parrot (Psittacus erithacus). Animal Learning \& Behavior, 14, 322-330.

Povinelli, D. J. (1989). Failure to find self-recognition in Asian elephants (Elephas maximus) in contrast to their use of mirror cues to discover hidden food. Journal of Comparative Psychology, 103, 122131.

Povinelli, D. J., Rulf, A. B., Landau, K. R., \& Bierschwale, D. T. (1993). Self-recognition in chimpanzees (Pan troglodytes): Distribution, ontogeny, and patterns of emergence. Journal of Comparative Psychology, 107, 347-372.

Robert, S. (1986). Ontogeny of mirror behavior in two species of great apes. American Journal of Primatology, 10, 109-117.

Robinson, J. A., Connell, S., McKenzie, B. E., \& Day, R. H. (1990). Do infants use their own images to locate objects reflected in mirrors? Child Development, 61, 1558-1568.

Ryan, M. J. (1978). Mirror image versus conspecific stimulation in adult male Zebra Finches. Wilson's Bulletin, 90, 295-297.

Stirling, I. (1968). Aggressive behavior and the dispersion of female blue grouse. Canadian Journal of Zoology, 46, 405-408.

Stout, J. F., Wilcox, C. R., \& Creitz, L. E. (1969). Aggressive communication by Larus glaucescens: Part I. Sound communication. Behaviour, 34, 29-41.

Striedter, G. F. (1994). The vocal control pathways in budgerigars differ from those in songbirds. Journal of Comparative Neurology, 343, 35-56.

Suarez, S.D., \& Gallup, G. G., Jr. (1981). Self-recognition in chimpanzees and orangutans but not gorillas. Journal of Human Evolution, 10, 175-188.

Swartz, K. B., \& Evans, S. (1991). Not all chimpanzees (Pan troglodytes) show self-recognition. Primates, 32, 483-496. 
Tinklepaugh, 0. L. (1928). An experimental study of representative factors in monkeys. Comparative Psychology, 8, 197-236.

Trillmich, F. (1976). Learning experiments on individual recognition in budgerigars (Melopsittacus undulatus). Zeitschrift für Tierpsychologie, 41, 372-395.

Wolter, A. (1987). African Grey parrots. New York: Barron.

Zazzo, R. ( 1975). Des jumeaux devant le miroir: Questions de methode [Twins in front of the miroir: methodological questions]. Journal de Psychologie, 4, 389-413.

Zazzo, R. (1979). Des enfants, des singes et des chiens devant la miroir. [About children, monkeys, and dogs in front of the mirror]. Revue de Psychologie Appliquee, 29, 235-246. 